\title{
Diversity study of Drumstick (Moringaoleifera Lam.) using Microsatellite markers
}

\author{
Amao A.O. ${ }^{1}$, Echeckwu C.A. ${ }^{2}$, Aba D.A. ${ }^{2}$, Katung M.D. ${ }^{2}$, Odeseye A.O. ${ }^{3}$ \\ ${ }^{1}$ Forestry Research Institute of Nigeria, Jericho Hills, Ibadan, Nigeria. \\ ${ }^{2}$ Department of Plant Science, Institute for Agricultural Research, Ahmadu Bello University, Zaria, Nigeria \\ ${ }^{3}$ Nigerian Institute of Science Laboratory Technology (NISLT),Samonda, Ibadan, Nigeria \\ Corresponding Author's email: funkebee2002@yahoo.com \\ Phone Number; +234 8180854553
}

\begin{abstract}
The study of the magnitude of genetic diversity existing within thirty one accessions of Moringaoleifera collections made within and outside Nigeria was conducted using ten Randomised Amplified Polymorphic DNA and tenMicrosattellite markers.None of the RAPD showed amplification bands. Five out of the Microsattellites markersamplified, four primers MO1, MO10, MO15 and MO41 were polymorphic in nature while the marker MO6 produced only a monomorphic band.PIC value was highest for the primer MO41 with 0.75 followed by primer $\mathrm{MO1}$ with 0.68 while, the lowest PIC value was recorded by the primer MO15 with 0.11.A total of 19 alleles were produced by the four primers and the number of alleles ranged from two to nine with an average of 4.75 alleles per primer. The maximum number allele frequency was generated by primer MO15 followed by MO10.The gene diversity varied from 0.12 to 0.78 with an average of 0.52 , PIC content of the SSR primers ranged from 0.11 to 0.75 with an average of 0.48 with primers MO 41 followed closely by primer MOI having maximum numbers of allele number, PIC and gene diversity. Hence, the primer pairs MO4land MO1 can be considered in future molecular studies of Moringaoleifera.The Cluster analysis was able to group the thirty one accessions into two main clusters with four sub clusters. Six of the accessions were found to be duplicated or closely related with one or two other accessions having 0.00 genetic distances between them. The clusters were having some accessions grouped based on same area of collection, however there still existed groupings that were not having link with area of collection.
\end{abstract}

Keywords-Moringaoleifera, molecular diversity, SSR Markers, gene diversity, PIC value.

\section{INTRODUCTION}

Moringaoleifera commonly known as drumstick is the most widely cultivated species of Monogenetic family, Moringaceae (Fuglie, 2013). A total of 13 tropical and subtropical species of the Moringa genus are known out of which some species such as $M$. arborea, M. borziana, M. longituba, M. rivae, M. ruspoliana, and M. stenopetala are endangered (Stephenson and Fahey, 2004). Moringaoleifera $\mathrm{L}$. is the only cultivated species in the Moringa genus (Sanchez et al., 2006). Moringaoleifera tree comprises of 4 different edible parts: leaves, pod, stem and root (Morton, 1991)which arewell known for their richness in proteins, minerals, and vitamins, the leaves of $M$. oleiferaare used as a highly nutrient vegetable and as cattle fodder (Mughal et al., 1999). In addition, the seed powder is used in water purification and the seed oil is acquired for edibles, lubrication, and cosmetics (Anwar and Bhanger, 2003). Genetic diversity has been described by Brown, (1983) as the amount of genetic variability among individuals of a variety or population of species resulting from many genetic differences between individuals and may manifest in differences in DNA sequence, in biochemical characteristics like protein structure, in physiological properties like abiotic stress resistance or growth rate, or in morphological characters such as flower colour or plant form. Genetic variation in plant is generally accepted to be structured in space and time (Rao and Hodgkin, 2001). Knowledge of population genetic diversity is one of the prerequisites for development of plant species conservation strategies there is a need for a highly reliable and precise method to detect the variation without any environmental effects. Variation among the provenances might be attributed to genetic differences caused by the adaptation of different provenances to diverse environmental conditions (Ginwalet al., 2005) and soil types (Elmagboulet al., 2014).

Molecular techniques have been applied to increase the understanding of the distribution and extent of genetic diversity within and between species. Molecular markers detect genetic variation within genotypes of interest at the DNA level.They are not influenced by environments, nor by pleiotrophism, or episttic interactions (Kameswara, 2004). They offer numerous advantages over conventional, phenotype-based alternatives as they are 
stable and detectable in all tissues regardless of growth, differentiation, development, or defence status of the cell they save time and cost (Tanksleyet al., 1989). Variability studies using molecular tools helps in identifying duplications within the collection, and the genetic linkage among the accessions which can be estimated and which are used in quantifying the genetic variability. Microsatellite or simple sequence repeats (SSR) markers are considered useful to these approaches, due to their effectiveness in genealogy analysis and in the assessment of genetic diversity among organisms (Narvelet al., 2000; Kuroda et al., 2009). It is thus important to determine the nature and magnitude of the diversity existing among accessions of drumstick ( $M$. oleifera)repository established in Forestry Research Institute of Nigeria to identify accessions that would be superior in terms of important characteristics using molecular primers to detect DNA polymorphism among collected accessions of drumstick and for selecting parents for further breeding program.Another focus is also to be able to improve the adaptability potential Moringaoleifera for future genetic diversity studies in Nigeria.

\section{MATERIALS AND METHODS}

The field study was conducted at the Forestry Research Institute of Nigeria, Jericho Ibadan South west, Nigeria, located on Longitude $07231^{0} \mathrm{~N}$ to $072343^{0} \mathrm{~N}$ and Latitude $035120^{\circ} \mathrm{E}$ to $035143^{\circ} \mathrm{E}$, with West African Monsoon climatehaving dry and wet season. The location has a mean annual rainfall of approximately $1548.9 \mathrm{~mm}$ within a period of 90 days. The mean maximum temperature is $31.9^{\circ} \mathrm{C}$ minimum $24.2^{\circ} \mathrm{C}$. Mean daily relative humidity is about $71.9 \%$ (FRIN, 2015). The laboratory analysis was carried out at Nigerian Institute of Science Laboratory Technology (NISLT), Samonda, Ibadan, Oyo- State and International Institute of Tropical Agriculture (IITA) Ibadan.The plant materials used for the genetic diversity study were collected from each of the 31 accessions of Moringaoleiferasix months after transplanting to the field. Leaf sample were carefully collected from a specifically randomly tagged plantin each plot of the 31 accessions. This was done at the tip of freshly growing branch early in the morning and the samples were refrigerated till they were ready for use. Genomic DNA samples were extracted using a RPN-8510 illustra DNA extraction kit Phytopure for plant DNA extraction. (Buckinghamshire, U.K).3g of young leaf tissue was ground with liquidnitrogen and to this powder $15 \mathrm{ml}$ of preheated CTABbuffer $\left(65^{\circ} \mathrm{C}\right)$ was added. It was then incubated at $65^{\circ} \mathrm{Cin}$ a water bath for one hour. After bringing the tubesto room temperature equal volume (15ml) ofchloroform: Isoamyl alcohol (24:1) was added and thecontents were mixed well for 10 minutes to form anemulsion. It was then centrifuged at $10,000 \mathrm{rpm}$ for 15 minutes at $15^{\circ} \mathrm{C}$. The supernatant was transferredto a fresh tube and the chloroform: isoamyl alcoholstep was again repeated. The aqueous phase wastransferred to a new tube and equal volume of icecold isopropanol was added and incubated in afreezer overnight. The contents were thencentrifuged at $10,000 \mathrm{rpm}$ for 20 minutes at $16^{\circ} \mathrm{C}$.The pellet was now saved by discarding the solution. The pellet was washed with $70 \%$ ethanol by centrifuging the contents at $10,000 \mathrm{rpm}$ for 10 minutes. The alcohol was discarded and the pellets air dried. The pellets were dissolved in $3 \mathrm{ml}$ of double distilled water thereafter $1 \mu \mathrm{l}$ of RNase was added and incubated at $37{ }^{\circ} \mathrm{C}$ for 30 minutes.DNA was precipitated by adding $50 \mu \mathrm{l}$ of $3 \mathrm{M}$ sodium acetate and $7.5 \mathrm{ml}$ of $100 \%$ ethanol and the contents were again centrifuged at $10,000 \mathrm{rpm} \mathrm{f}$ or 10 minutes.Supernatant was discarded. The pellet was washedwith $70 \%$ ethanol and air dried. It was finally dissolved in TE buffer $(150 \mu \mathrm{l})$ and stored at $-20^{\circ} \mathrm{C}$ for long term use.The quantification of the DNA was carried out using a Nanodrop.. Ten Microsatellite primers were randomly selected from the list prepared by $\mathrm{Wu}$ and Yang (2010) for Moringaoleiferawhich were used for the genotyping. The PCR was carried out with an initial denaturing at $95{ }^{0} \mathrm{C}$ for $5 \mathrm{~min}$, followed by 30 cycles of 94 ${ }^{0} \mathrm{C}$ for $30 \mathrm{~s}$, primer- specific annealing temperature 55 to $61{ }^{\circ} \mathrm{C}$ for $30 \mathrm{~s}, 72{ }^{\circ} \mathrm{C}$ for $30 \mathrm{~s}$ and a final extension at 72 ${ }^{0} \mathrm{C}$ for $8 \mathrm{~min}$ and a hold at $4{ }^{0} \mathrm{C}$. For enrichment of the fragments containing SSRs, the PCR products, with a size range of 200 to $1000 \mathrm{bp}$, were denatured at $95{ }^{\circ} \mathrm{C}$ for 5 min and were then hybridized with $5^{1}$ biotinylatedprobe (AG) in a $250-\mathrm{mL}$ solution (4.16 $\cdot \mathrm{SSC}$ and $0.07 \% \mathrm{SDS}$ ) at $48{ }^{\circ} \mathrm{C}$ for 2 hours. The mixture was incubated at room temperature for $30 \mathrm{~min}$ with constant gentle agitation. The amplified products were then electrophoresed in $8 \%$ polyacrylamide gels and the amplified fragments were visualized by silver staining as described by Bassamet al. (1991). Electrophoretic patterns were scored and checked with a 20-bp DNA ladder marker (Takara, Tokyo) used to estimate allele sizes. The gel pictures were recorded using Gel Documentation System. The SSR electrophoretic profile of each gel was transformed into a binary matrix of visible presence (1) and absence (0). The SSR data were subjected to analysis to determine the major Allele Frequency, Genetic Diversity and Polymorphic Information Content (PIC). Polymorphic Information Content (PIC) is a parameter that provides an estimate of the discriminatory power of molecular marker per primer and this was calculated using Power Maker 3.5 (Liu and Muse, 2005). Genetic distances across the accessions and neighbour joining trees were calculated using Power Maker 3.5. 


\section{RESULTS}

\section{Primers Characteristics}

10 RAPD primers and 10 Microsatellite SSR markers were used for the study, however none of the RAPD primers amplified at the electrophoresis stage. From the 10 Microsatellites SSR markers that were used 5 produced amplified bands which were scored and used in the assessment of the genetic diversity. Four out of the markers MO1, MO10, MO15 and MO41 as shown in Figures (1a, 1c, 1d and 1e) respectively were polymorphic in nature while the marker MO6 Fig 1b produced only a monomorphic band. Polymorphism Information Content (PIC) value was calculated for four polymorphic primers out of the five primers used in the analysis as given in the Table1. PIC value which estimates the quantity of information that can be obtained from a particular primer was highest for the primer MO41 with 0.75 followed by primer MO1 with 0.68 while, the lowest PIC value recorded by the primer MO15 with 0.11. The mean PIC value for 4 polymorphic primers was 0.481 . Polymorphic Information Content (PIC) reveals the quantity of information that can be obtained from a particular primer. The polymorphic information content (PIC) ranged from 0.1134 for MO15 to 0.7519 for MO41 with an average of 0.4813 .

The gene diversity ranged from 0.1207 for MO15 to 0.7825 for MO41 with average value of 0.5224 . The major allele frequency calculated ranged from 0.3226 for MO41 to 0.9355 for MO15 with average of 0.5726 . The four SSR markers produced 19 alleles and the number of alleles ranged from 2 to 9 with an average of 4.75 alleles per locus in the 31 accessions. The maximum number of amplified products was generated by primer MO41 with nine alleles followed by MO1 with 5 alleles. Temperature of amplification for the SSR markers ranged from $55^{\circ} \mathrm{C}$ for MO 41 to $61^{\circ} \mathrm{C}$ for MO6. These were used in generating amplification profiles for the 31individual accessions of Drumstick.

\section{Cluster Analysis from the SSR markers}

The cluster analysis from the Molecular diversity using five Microsatellite markers generated a dendrogram which is presented in Fig 2 below. Molecular analysis using SSR markers was able to group the 31 accessions into two main clusters (1 and 2) separating at 0.04 and 0.13 coefficients. At 0.04 coefficients, cluster 1 , there are two distinct accessions FRIN MOR12-27 and FRIN MOR12-31 that are clustered. The remaining 29 accessions are clustered at 0.13 coefficients. At 0.13 coefficients, there are two distinct sub clusters $2 \mathrm{a}$ and $2 \mathrm{~b}$. At 0.08 coefficients (Cluster 2a) six accessions clustered together and the remaining twenty three accessions were clustered at 0.06 coefficients (Cluster 2b). At 0.57 similarity index cluster 2 had two separate distinct clusters that grouped the remaining twenty nine accessions. At 0.43 the remaining twenty nine accessions were grouped into two sub clusters having 0.08 and 0.06 coefficients. At 0.08 coefficients six accessions were grouped with their genetic difference having FRIN MOR12-2 at 0.35, FRIN MOR12-10 at 0.31. At 0.17 genetic distances FRIN MOR12-15, FRIN MOR12-4, FRIN MOR12-26 and FRIN MOR12-13 are sharing same genetic composition. The other sub cluster (2bi) of 0.06 was sub clustered with the rest accessions at 0.39 , at this coefficient, nine accessions are sub clustered. 29\% (nine out of thirty-one) of the accessions under study clustered at this distributing them at different genetic distance. The cluster comprised of FRIN MOR12-1, FRIN MOR12-23, FRIN MOR12-18, FRIN MOR12-14, FRIN MOR12-19, FRIN MOR12-5, FRIN MOR12-8, FRIN MOR12-3 and FRIN MOR12-7 respectively. Under sub cluster $2 \mathrm{~b}$ (ii), $45.2 \%$ (fourteen out of thirty one) the rest of the accessions were grouped together at 0.39. Cluster 2bi comprised of: FRIN MOR12-29, FRIN MOR12-24, FRIN MOR12-25, FRIN MOR12-30, FRIN MOR12-21, FRIN MOR12-28, FRIN MOR12-20, FRIN MOR12-9, FRIN MOR12-11, FRIN MOR12-6, FRIN MOR12-12, FRIN MOR12-16, FRIN MOR12-17 and FRIN MOR1222. They were grouped at various genetic distances having 0.16 and 0.11 coefficient of genetic distance. At 0.16 six accessions: FRIN MOR12-29, FRIN MOR12-24, FRIN MOR12-25, FRIN MOR12-30, FRIN MOR12-21 and FRIN MOR12-28 were clustered together. The remaining eight accessions were clustered at coefficient 0.11 having 0.04 genetic distance level in-between them. Generally, the result from the dendrogram at 0.00 genetic distance showed some duplications among the accessions in FRIN MOR12- 15 and FRIN MOR12- 4; FRIN MOR12-23 and FRIN MOR12-18; FRIN MOR12-8, FRIN MOR12-3 and FRIN MOR12-7; FRIN MOR1229,FRIN MOR12-24 and FRIN MOR12-25; FRIN MOR12-21 and FRIN MOR12-28 also FRIN MOR12-9, FRIN MOR12-11 and FRIN MOR12-6.

\section{DISCUSSIONS}

The Microsatellite SSR markers analysis gave the polymorphic Information Content average value of approximately 0.5 in this study. This agrees with the results of Salvakumari and Ponnuswami (2015) in their genetic study on 34 ecotypes of Moringaoleifera using 20 SSR markers. A contrary result was obtained by Ganessanet al. (2014) who reported an average PIC value of 0.15. Saini et al. (2013) used RAPD, ISSR, Cytochrome $\mathrm{P}_{450}$ markers also for Moringaoleifera and reported high PIC values of $0.72,0.81$ and 0.68 respectively which are all higher compared to what was obtained in SSR marker. The average gene diversity value 
is 0.52 in this study also indicates a wide variability among the accessions. A contrary result was observed by Ganesanet al. (2014) study on Moringaoleifera using SSR markers who reported gene diversity range between 0.01 and 0.49 with an average of 0.18 . The amplified alleles with an average value of 4.75 alleles per locus in the 31 accessions is also contrary to the report of Ganesanet al. (2014) of 35 alleles with an average of 1.84 per locus in diversity assessed in their study with 300 individuals of Moringaoleiferausing SSR markers. Kuo (2002) reported 75 RAPD markers with an average of 6.98 bands per primer. This is much higher than SSR markers. Muluviet al. (1999) also reported 59 bands per primer with AFLP. It is clearly seen that SSR markers produce the least number of bands. This is because they are locus specific and normally only two allelles are expected from each locus. The molecular analysis in this study show a relatively high polymorphism and gene diversity this indicates sufficient polymorphism exists within the present collection showing high level of variability and can be exploited for genetic linkage maps. With insufficient SSR markers the efficiency of the selected markers is also reflected. Primers MO1 and MO41 should be considered in future study for the genetic resource management inMoringaoleifera.

The cluster analysis of 31 Moringaoleifera accessions based on UPGMA suggested the formation of two main clusters with four sub clusters formed at different genetic distances. The clustered groups comprised of accessions from different ecological locations being grouped together, there is no clear geographical isolation of the accessions studied. This might be attributed to genetic component, breeding system and phenotypic similarities. The accessions were raised in a common environment and subjected to similar treatments which invariably might have reduced the effects of the environment on their phenotypic expression. The absence of clustering based on geographical location indicates that individuals from different locations are not significantly different genetically. This is similar to previous report on ninety seven accessions using SSR markers in India by Rajalakshmiet al. (2017); Ganesanet al. (2014) and Rufaiet al. (2013) using RAPD markers. Clustering of individuals from the same population in different clusters indicates high genetic variation within population which may be attributed to the use of seed sources or breeding system which is in agreement with the fact that it is predominantly an out-crossed plant Mgendiet al. (2010). However, the results are contrary to the study of Muluviet al. (1999) where clustering of accession was based on their geographic origin. The dendrogram from the cluster analysis after clearly showing the genetic diversities among the accessions went further to show that 15 of the accessions were duplicated or closely related based on the primers used in this study and the 15 accessions were now grouped into just 6 accessions. This duplication or close relationship could have resulted from low level of genetic distances between the concerned accessions or resulting from low frequency of the allele obtained with the five primers used in this study. The similarities may also be as a result of gene flow between adjacent populations or spread from cuttings and seeds used in planting although Muuluviet al. (1999); Zenglu and Randal (2002) had reported grouping of genotypes based on geographic origin. It is inferred from the cluster analysis that Cluster 1 and cluster $2 \mathrm{a}$ are most differed at the molecular level and the accessions in the clusters can be employed in improvement programme of Moringaoleifera. The results from this research have shown that enough variability and genetic heritability exist in the studied characters among the evaluated 31 accessions of drumstick. These observations indicate great diversity exists between the accessions and also demonstrate that the selected primers are highly informative and useful for further studies on Moringaoleifera genetic diversity study and improvement programmes.

\section{CONCLUSIONS}

Genetic diversity of Moringaoleiferais effectively investigated using SSR or microsatellite markers, which allow a more complete coverage of the existent genetic variation. The genetic diversity of the investigated accessions is relatively high, distributed over two main clusters and four sub clusters, and exhibits a moderate level of association between genetic divergence and geographical origin of accessions. This species shows diversifications and may become a resource for the conservation and the selection of Moringaoleiferagermplasm.

Table.1: Status of SSR markers used with respect to allele frequency, allele number, gene diversity and polymorphic information content (PIC)

\begin{tabular}{|c|c|c|c|c|c|c|c|c|}
\hline Marker & & $\begin{array}{l}\text { Allele } \\
\text { Frquency }\end{array}$ & SampleSize & $\begin{array}{l}\text { No. of } \\
\text { obs. }\end{array}$ & AlleleNo & Availability & GeneDiversity & PIC \\
\hline MO1 & $\begin{array}{l}\text { F TTGTCTGCCTCCTTTTGTCA } \\
\text { R AACTGTCACCCTCCTATCCA }\end{array}$ & 0.3548 & 31 & 31 & 5.0000 & 1.0000 & 0.7305 & 0.6827 \\
\hline MO6 & F GCATAGCCACCTTTACTCCT & - & 31 & 31 & - & 1.0000 & - & - \\
\hline
\end{tabular}




\begin{tabular}{|c|c|c|c|c|c|c|c|c|}
\hline \multirow{3}{*}{ MO10 } & R GACTTTTGAАCTCCACCACC & \multirow[b]{2}{*}{0.6774} & \multirow[b]{2}{*}{31} & \multirow[b]{2}{*}{31} & \multirow[b]{2}{*}{3.0000} & \multirow[b]{2}{*}{1.0000} & \multirow[b]{2}{*}{0.4558} & \multirow[b]{2}{*}{0.3773} \\
\hline & F CTTTACACCTCAGTATCCCT & & & & & & & \\
\hline & R GTTCGGCTTATGTTCTCGTT & & & & & & & \\
\hline \multirow[t]{2}{*}{ MO15 } & F ССССТСТАТТTССАТTTТСC & 0.9355 & 31 & 31 & 2.0000 & 1.0000 & 0.1207 & 0.1134 \\
\hline & R GCTCCATAАACCCTCTTGCT & & & & & & & \\
\hline \multirow[t]{2}{*}{ MO41 } & R TAGTGGGTCCAAGACAAAGC & 0.3226 & 31 & 31 & 9.0000 & 1.0000 & 0.7825 & 0.7519 \\
\hline & F TGGGATTAGGGCATTAGAAA & & & & & & & \\
\hline Mean & & 0.5726 & 31 & 31 & 4.7500 & $\mathbf{1 . 0 0 0 0}$ & 0.5224 & 0.4813 \\
\hline
\end{tabular}

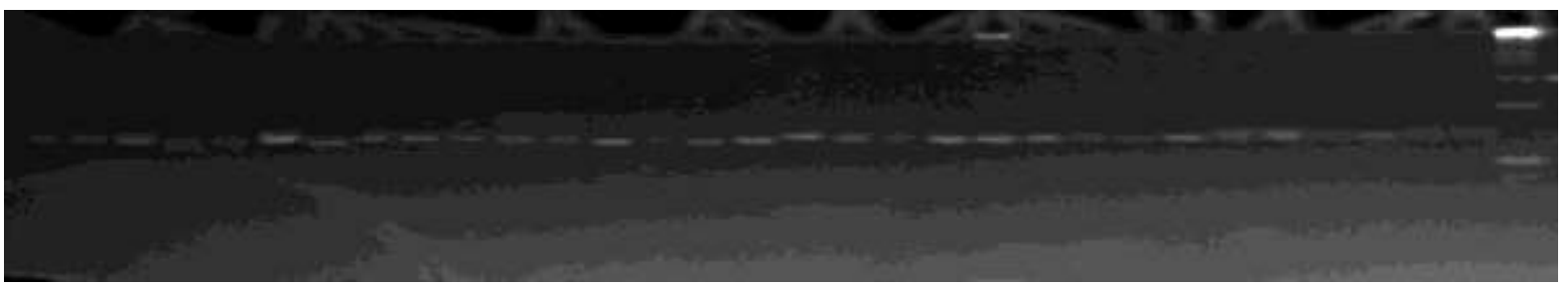

Fig.la PRIMER 1(MO1)F TTGTCTGCCTCCTTTTGTCA

R AACTGTCACCCTCCTATCCA

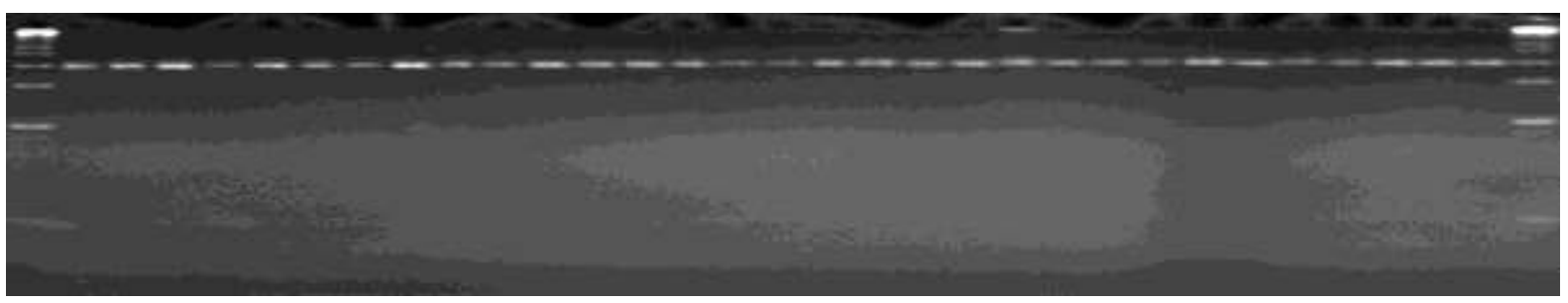

Fig.1b PRIMER2 (MO6) F GCATAGCCACCTTTACTCCT

$R$ GACTTTTGAACTCCACCACC

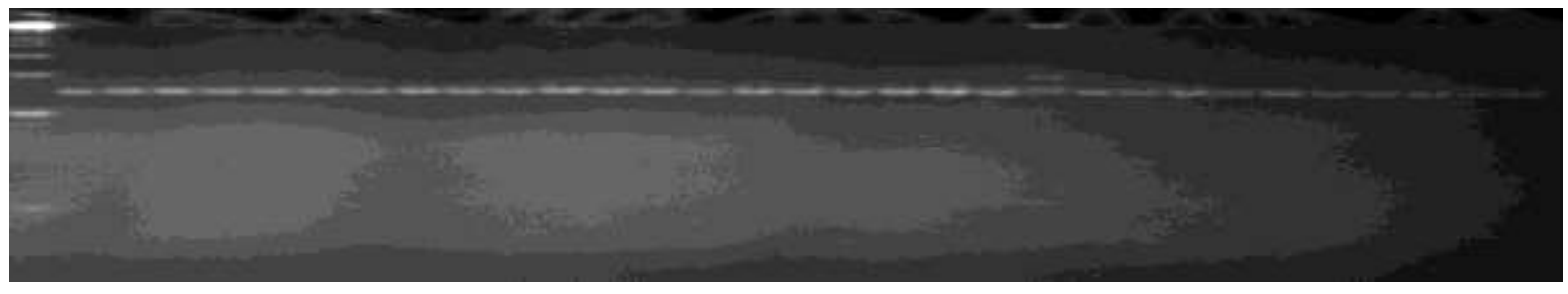

Fig.lc PRIMER $3(\mathrm{MOIO}) \quad$ F CTTTACACCTCAGTATCCCT

R GTTCGGCTTATGTTCTCGTT

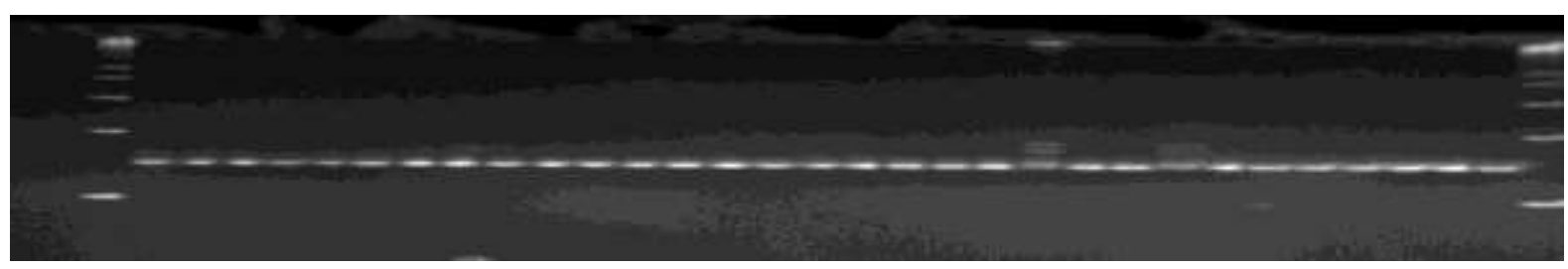

Fig.1d PRIMER4 (MO15) F CCCCTCTATTTCCATTTTCC

R GCTCCATAAACCCTCTTGCT

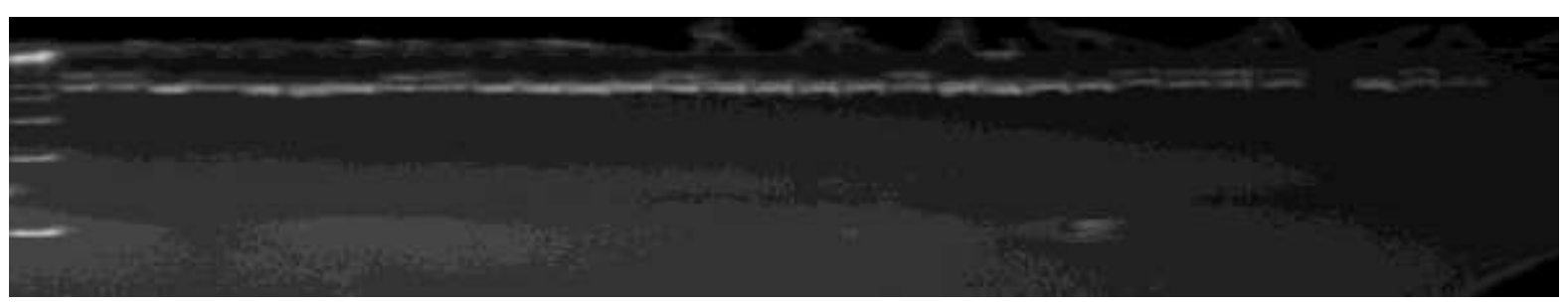

Fig.le PRIMER5(MO41) R TAGTGGGTCCAAGACAAAGC 


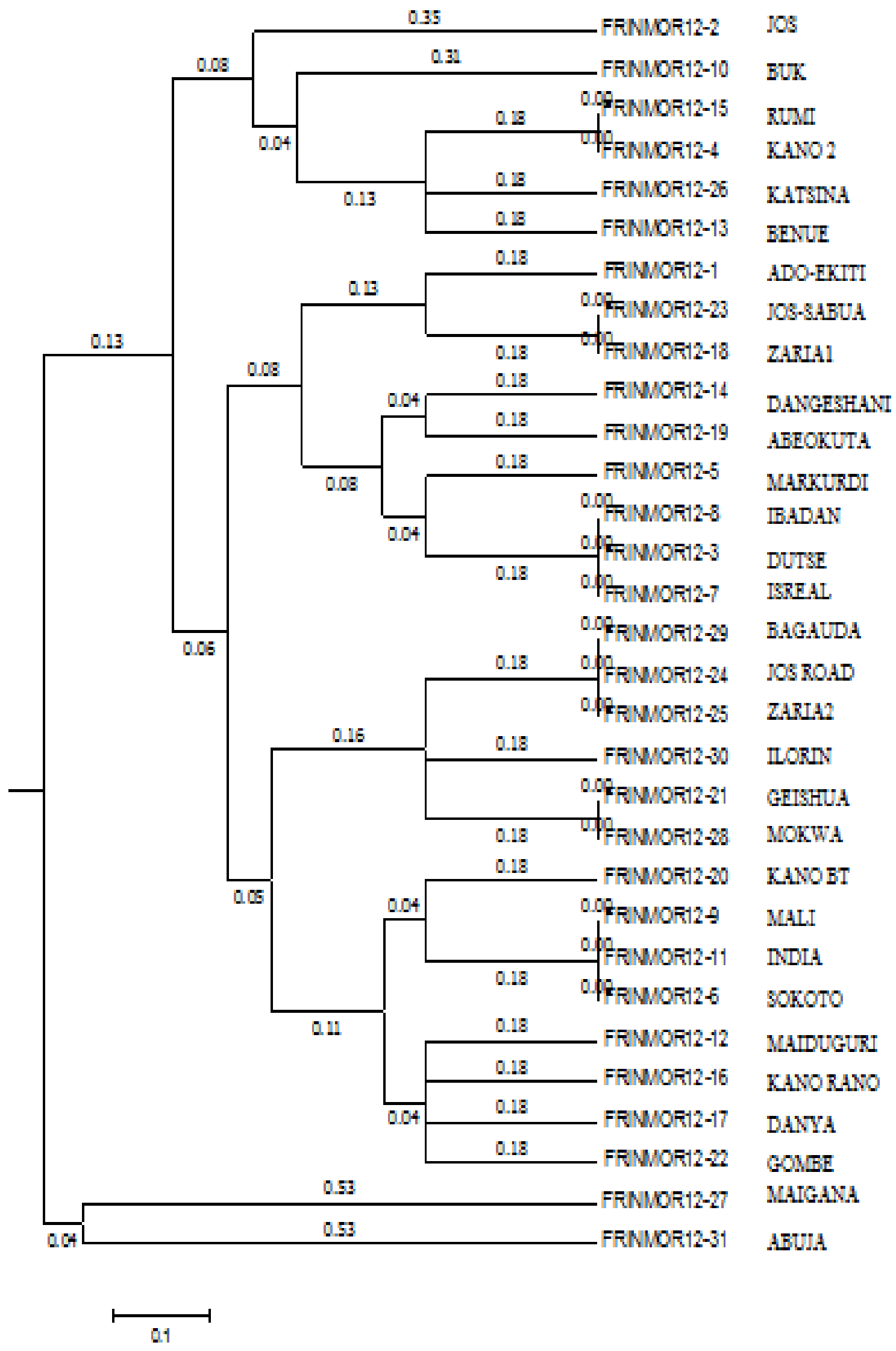

Fig.2: The Dendrogram generated from the cluster analysis 
[1] Anwar F, Bhanger M., (2003).Analytical characterization of Moringaoleifera seed oil grown in temperate regions of Pakistan. J Ag Food Chem 51:6558-6563

[2] Brown,W.L. (1983). Genetic diversity and genetic vulnerability- An appraisal.Econ.Bot. 37(1): 4-12

[3] Elmagboul, H., Mahgoup, S., Eldoma, A. (2014). Variation in seed morphometric characteristics and germination of Acacia tortilissubspecies raddiana and subspecies spirocarpaamong three provenances in Sudan.Global Journal of Bio-Science and Biotechnology. 3(2): 191-196.

[4] FRIN (2015). Forestry Research Institute of Nigeria, Annual Meterological Report.

[5] Fugile, L. T., (2013): Moringaoleiferanatural nutrition for the tropics, Dakar world Service published as the miracle trees.

[6] Ganesan, S.K.; Singh, R.; Roy Choudhury, D.; Bharadwaj, J.; Gupta, V.; Singode, A. 2014. Genetic diversity and population structure study of drumstick (MoringaoleiferaLam.) using morphological and SSR markers. Ind. Crop. Prod. Vol. 60, 316-325.

[7] Kuo, G. (2002). Annual Report.Asian Vegetable Research Development Centre, Taiwan, pp.133-134.

[8] Kuroda, Y.; Tomooka, N.; Kaga, A.; Wanigadeva, S.M.S.W.; Vaughan, D.A. (2009).Genetic diversity of wild soybean (Glycine sojaSieb.EtZucc.) and Japanese cultivated soybeans [G.max (L.) Merr.]based on microsatellite (SSR) analysis and the selection of a core collection. Genetic Resources and CropEvolution, v.56, p.1045-1055.

[9] Mgendi, M., Manoko, M., Nyomora, A.M. (2010) A. Genetic diversity between cultivated and noncultivated MoringaoleiferaLam. provenances assessed by RAPD markers .Journal of Cell Molecular Biology, 8, 95-102.

[10] MondiniLinda, ArshiyaNoorani and Mario A. Pagnotta (2009) Assessing plant genetic diversity by Molecular tools. Diversity Vol. 1, 19-35. www.mdpi.com/journal/diversity

[11] Morton, J.F.,(1991). The horseradish tree, Moringapterygosperma (Moringaceae) - A boon to Arid Lands?Econ.Bot.45, 318-333.

[12] Muluvi, G. M., Sprent, J. L., Soranzo, N., Provan, J., Odee, D., Folkard. G., McNicol, J. W., Powell, W. (1999). Amplified fragment length polymorphism (AFLP) analysis of genetic variation in MoringaoleiferaLam. Molecular Ecology. 8: 463470.

[13] Muluvi, G.M.; Sprent, J.I.; Odee, D.; Powell, W. (2004). Estimates of outcrossing rates in
Moringaoleiferausing Amplified fragment length polymorphism (AFLP). Afr. J. Biotechnol., 3,145151

[14]Rajalakshmi R., Rajalakshmi S., and Parida Ajay (2017). Evaluation of the genetic diversity and population structure in drumstick (MoringaoleiferaL.) using SSR markers. Current Science 112. 6, 25. doi: 10.18520/cs/v112/i06/12501256

[15]Rao, V. Ramanatha and Hodgkin, Toby (2001).Genetic diversity and conservation and utilization of plant genetic resources.Plant Cell, Tissue and Organ Culture 68: 1-19

[16] Rufai, S., Hanafi, M.M., Rafii, M.Y., Ahmad, S., Arolu, I.W., Ferdous, J. (2013). Genetic Dissection of New Genotypes of Drumstick Tree (Moringaoleifera Lam.) Using Random Amplified Polymorphic DNA Marker. BioMed Research International, http://dx.doi.org/10.1155/2013/604598

[17] Saini, R.K., Saad, K.R., Ravishankar, G.A., Giridhar, P., and Shetty, N.P. (2013). Genetic diversity of ommercially grown Moringaoleifera Lam. cultivars from India by RAPD, ISSR and cytochrome P450-based markers. Plant System Evolution 299, 1205-1213.

[18] Salvakumari P., and Ponnuswami V., (2015) Genetic diversity of Moringaoleifera using SSR markers .International Journal of Tropical Agriculture. 33, No2 943-946

[19] Sanchez N, Sporndly E, Ledin I (2006) Effect of feeding different levels of foliage of Moringaoleifera to creole dairy cows on intake, digestibility, milk production and composition. Livestock Sci 101:2431

[20] Stephenson K, Fahey J (2004) Development of tissue culture methods for the rescue and propagation of endangered Moringa spp. germplasm.Econ Bot 58:S116-S124

[21] Tanksley, S. D., Young, N. D., Paterson, A. H andBonierbale, M. W. (1989). RFLP mapping in plant breeding: Newtools for an old science. Biotechnol., 7: 257-264.

[22] Wu, J.C.; Yang, J.; Gu, Z.J.; Zhang, Y.P. 2010. Isolation and characterization of twenty polymorphic microsatellite loci for Moringaoleifera(Moringaceae).HortScienceVol.,45, 690-692.

[23]Zenglu, L., and Randall, L.N. ( 2002). RAPD marker diversity among cultivated and wild Soybean accessions from four Chinese provinces. Crop Science. 42, 1737-1744. 